\title{
Processing of $\mathrm{Cu}-\mathrm{Cr}$ alloy for combined high strength and high conductivity
}

\author{
A.O Olofinjana ${ }^{\mathrm{a}, *}$, A. and K. S. Tan \\ ${ }^{a}$ Faculty of Science, Universiti Brunei Darussalam, Jalan Tungku Link, BE1410, Brunei Darussalam
}

*Corresponding author. E-mail address: ayodele.olofinjana@ubd.edu.bn

\begin{abstract}
High strength and high conductivity (HSHC) are two intrinsic properties difficult to combine in metallic alloy design because; almost all strengthening mechanisms also lead to reduced conductivity. Precipitation hardening by nano-sized precipitates had proven to be the most adequate way to achieve the optimum combination of strength and conductivity in copper based alloys. However, established precipitation strengthened $\mathrm{Cu}$ - alloys are limited to very dilute concentration of solutes thereby limiting the volume proportion hardening precipitates. In this work, we report the investigation of the reprocessing of higher $\mathrm{Cr}$ concentration $\mathrm{Cu}$ - based alloys via rapid solidification. It is found that the rapid solidification in the as-cast ribbon imposed combined solution extension and ultra-refinement of $\mathrm{Cr}$ rich phases. X-ray diffraction evidences suggest that the solid solution extension was up to $6 \mathrm{wt} \% \mathrm{Cr}$. Lattice parameters determined confirmed the many folds extension of solid solution of $\mathrm{Cr}$ in $\mathrm{Cu}$. Thermal aging studies of the cast ribbons indicated that peak aging treatments occurred in about twenty minutes. Peak aged hardness ranged from about 200 to well over 300Hv. The maximum peak aged hardness of $380 \mathrm{Hv}$ was obtained for alloy containing $6 \mathrm{wt} . \% \mathrm{Cr}$ but with conductivity of about 50\%IACS. The best combined strength/conductivity was obtained for $4 \mathrm{wt} . \% \mathrm{Cr}$ alloy with hardness of $350 \mathrm{HV}$ and conductivity of $80 \%$ IACS. The high strengths observed are attributed to the increased volume proportion of semi-coherent $\mathrm{Cr}$ rich nano-sized precipitates that evolved from the supersaturated solid solution of $\mathrm{Cu}-\mathrm{Cr}$ that was achieved from the high cooling rates imposed by the ribbon casting process. The rapid overaging of the high $\mathrm{Cr}$ concentration $\mathrm{Cu}-\mathrm{Cr}$ alloy is still a cause for concern in optimising the process for reaching peak HSHC properties. It is still important to investigate a microstructural design to slow or severely restrict the overaging process. The optimum HSHC property reported here is a rare combination of high strength $(>350 \mathrm{Hv} \sim 900 \mathrm{MPa})$ and conductivity $(50-80 \%$ IACS $)$ found in metallic alloys.
\end{abstract}

Keywords: Metallic alloys; Cu-alloys; Mechanical Properties; Electrical Properties; Aging; Precipitation hardening 


\section{Introduction}

Copper based alloys are now widely used in applications where good electrical and thermal conductivities are the required functional properties. Pure and annealed copper has extremely good electrical conductivity that it now forms the basis for describing the electrical conductivity of conductor materials in percentage relative to its conductivity (\% IACS). Though pure copper has appreciable electrical conductivity and it is the natural choice materials for most electrical applications, it has a rather weak mechanical strength. In many electrical and thermal (conductivity) applications where mechanical strength is of little significance, pure copper or lightly alloyed $\mathrm{Cu}-\mathrm{Sn}$ alloys have been the materials of choice. Typically, such alloys can only be strengthened by cold work. However, improving strengths from cold work have its limits due to self annihilation of dislocation at room temperature from dynamic recovery [1].

In applications such as electrical contacts and lead frame materials, where the mechanical strengths as well as electrical conductivity are required, the need arise for an alloy with combined property of high strength and high conductivity (HSHC). In attempts to consider the development of HSHC alloys, it is important to understand fundamentals of the metallurgical factors that contribute to the overall conductivity of a processed metal. Fundamentally, the resistivity ( $\rho$ ) (and therefore conductivity $(\sigma)$ ) of a metal is the sum effect of all factors that contribute to the scattering of electron (being the charge carrier in electrical conductivity) and is governed by the Mathiessen's rule:

$$
\rho_{\text {overal }}=\rho_{t}+\rho_{b}+\rho_{i}+\rho_{d}
$$

where, $\rho_{t}, \rho_{b}, \rho_{i}$ and $\rho_{d}$, are respectively the contributions of thermal vibration, grain/phase boundaries, and dislocation, to electron scattering. It is quite clear then that the traditional mechanism for strengthening, grain refinement, solid solution and cold work are respectively associated with $\rho_{b}, \rho_{i}$ and $\rho_{d}$, and each would inevitably contribute to increase resistivity or reduce conductivity. The contribution from impurity $\left(\rho_{i}\right)$ is particularly very significant such that for very dilute concentrations of impurity elements, the conductivity of copper would drop rapidly enough for it to have any practical functional electrical use. For this reason, it is difficult to employ any of these strengthening mechanisms that required extensive alloying and unavoidable solid solution in $\mathrm{Cu}$ - based alloys and still retains appreciable conductivity. In fact it is quite rare to find $\mathrm{Cu}$ - based alloy with yield strength higher than $500 \mathrm{MPa}$ and with conductivity higher than $80 \%$ IACS. It is now the convention to class alloys with hardness above $120 \mathrm{Hv}$ or yield strength above $500 \mathrm{MPa}$ and with conductivity above $70 \%$ IACS as a HSHC alloy.

Several attempts have been devoted to developing HSHC copper alloys and most of these [2-6] are targeting precipitation hardening systems. This is because this approach provided the strengthening strategy that offers more resistance to dislocation motion and less contribution to the scattering of free electrons and thus reduced resistivity in line with equation (1). Many analyses [7, 8] of the strengthening mechanism in the $\mathrm{Cu}-$ based systems suggest that the extent of hardening is directly proportional to the square root of the volume fraction of the hardening dispersed precipitates. The general approach therefore is to attempt to increase the volume proportion of the hardening second phases in a morphological distribution that doesn't significantly affect the scattering of electrons and result in increased resistivity. The conventional processing via ingot metallurgy has reached the limits allowed by the thermodynamic and kinetic factors such that new inroads are now only possible via non equilibrium processing routes that are embracing newer technologies. HSHC properties have been reported in $\mathrm{Cu}-\mathrm{Ta}$, 
$\mathrm{Cu}-\mathrm{Ta} / \mathrm{Zr}, \mathrm{CuNb}, \mathrm{CuCr}$. These have in common that the solute elements have severely limited solid solubility at low temperatures. Non equilibrium processing such as powder processing [3, 5, 8-9], rapid solidification [8 -13], mechanical alloying[14] have been employed to trap more solute in solution so that the alloy can be heat-treated to give optimum combination of strength and conductivity. The $\mathrm{Cu}-\mathrm{Cr}$ in particular has been widely studied (e.g. [2, 3, 10-11]) because of the extremely low solid solubility of $\mathrm{Cr}$ in copper and because of the morphology of $\mathrm{Cr}$ rich non equilibrium precipitates that could arise from aging. However, most of these studies [2, 3, 6] are limited to low $\mathrm{Cr}$ content typically less than 2 weight percent. The problem with higher $\mathrm{Cr}$ content alloys stem with the difficulty of preparing homogeneous alloys in higher concentration because $\mathrm{Cr}$ in copper tend to give macro segregation in relatively large ingots. Here in this work we have looked at the higher $\mathrm{Cr}$ alloys by preparing the master alloy through smaller semi chilled ingots that prevent macro-segregation of the chrome content.

\section{Experimental}

\subsection{Alloy Preparation}

$\mathrm{Cu}-\mathrm{Cr}$ alloys were prepared from the re-melting of pure electrolytic copper and chromium. An alloy batch was melted in an alumina crucible using a medium frequency induction furnace over a stream of high purity argon. The furnace prior to melting was evacuated to $10^{-5}$ torr and was backfilled to maintain a slightly positive pressure of the protective argon gas. Upon melting and mixing, the melt was vacuum sucked into quartz tubes of diameter $7 \mathrm{~mm}$. The sucked melt was then quenched into water in order to prevent macro-segregation of $\mathrm{Cr}$ that typically accompany $\mathrm{Cu}-\mathrm{Cr}$ ingot with high $\mathrm{Cr}$ content. Wet chemical analysis and electron microprobe were used to further confirm the bulk compositions of semichilled ingots.

\subsection{Ribbon casting and heat treatment.}

Ribbons were produced in batches of about $20 \mathrm{~g}$ through chill block melt spinning similar to that described in [18] of about $20 \mathrm{~g}$ of re-melted alloy ingot. The ingot was loaded unto a quartz nozzle with diameter of about $800 \mu \mathrm{m}$. The melt spinning chamber was evacuated to $10^{-5}$ torr and backfilled with high purity argon to a pressure of about one third atmospheres.

Samples for heat treatment were sealed in a vicor tube previously evacuated to $10^{-5}$ torr and back filled with Ar gas to a pressure of one third atmospheres. Heat treatments were carried out isochronally (1hr) at temperatures ranging from $400-600^{\circ} \mathrm{C}$, in a tube furnace with an external thermocouple attached to monitor temperatures.

\subsection{Microstructure and Structural characterisation}

Microstructural observations were done with optical, Scanning and Transmission electron microscope. Most of the observations for the ingot were done in the un-etched condition because the phase contrast was resolved due to the differential wear rates of phases during polishing. Light etching with alcoholic ferric chloride were used in the case of cast ribbon to enhance the microstructures. SEM observations were done with Vega TC environmental SEM in backscattered and secondary electron mode. For most observations, accelerating voltage of $20 \mathrm{kV}$ was used. Chemical analysis was carried out on JEOL JXA- 8800L electron probe micro anaylser, with Wave length dispersive spectrometer (WDS) which gave quantitative information of micro-constituent in the ingot and rapidly solidified alloys. 
Qualitative information for microanalysis was obtained using the attached energy dispersive spectroscopy (EDS). For EDS observation, accelerated voltage was kept at 10kV to allow excitation of $\mathrm{Cr} \mathrm{K}_{\alpha}$ in the precipitates and limit the volume of interaction in the surrounding matrix.

TEM was used to supplement information from other techniques especially for characterizing microstructures in the aged samples. Thin sections were prepared by ion beam milling with liquid nitrogen cooling. Imaging in the TEM was performed with beam direction close to $\mathrm{Cu}[1,0,0]$ direction.

The phase composition of as cast ribbon was determined by $\mathrm{XRD}$ using $\mathrm{Cu} \mathrm{K}_{\alpha}$ radiation. XRD experiments were conducted with $2 \theta$ varied from $15^{\circ}$ to $150^{\circ}$ in order to cover the major $\mathrm{Cu}$ lines. The diffraction information was processed to get information about lattice parameter variation in order to infer extent of solid solution in the as cast alloys.

\subsection{Characterising HSHC properties}

Microhardness measurements were conducted on quenched sided of ribbon with a diamond pyramid indentor with a load of $15 \mathrm{~g}$. This typically gave statistically acceptable values of Vickers hardness over 10 measurements. Standard errors values calculated to measure variability in the hardness values were consistently less than $10 \mathrm{Hv}$. In order to complement the hardness measurements, a few samples were selected for tensile tests, using methods for amorphous fibers described in [15]. The values of yield strengths were too varied but nevertheless gave nominal average values consistent with the trends observed in the hardness values. For discursive purposes, the literature established yield strength/hardness ratio of 3-4 for this family of alloys was used to evaluate the true strength.

Electrical resistivity measurements were using standard bridge resistance measurements as prescribed in ASTM book of standards [16]. Since ribbon measurements involve a very thin section and in order to avoid errors with sectional area, an equivalent area value was deduced using density values for pure $\mathrm{Cu}$. The conductivity in \%IACS was deduced according to the equation [16]:

$$
\% I A C S=\frac{1724}{\rho}
$$

where $\rho$ is the electrical resistivity measured in $n \Omega m$.

\section{Results and Discussion}

\subsection{As cast ingot and ribbon alloys}

Figure 1 shows the morphology of the free and quenched surfaces of the cast ribbon. Both surfaces show features that translate to non-uniform cross section. On the quenched side, the chilling effect is evident, though the micrograph suggests some local variation in solidification rates. On the free side, evidence of melt flow and slower solidification rate is reflected in the wavelike nature. Since this surface takes relatively longer time to cool, the observation is consistent with melt disturbance from the shear force imposed by the casting process. HSHC results reported here are mostly based on measurements taken on the chill side. The irregularity of the cross section in particular posed some difficulty with estimating geometry related properties like strength and resistivity. In the case of resistivity, an effective area, derived from length and density of ingot alloy was used. For mechanical evaluation, we confined our measurements mostly to indentation on the chill side. 

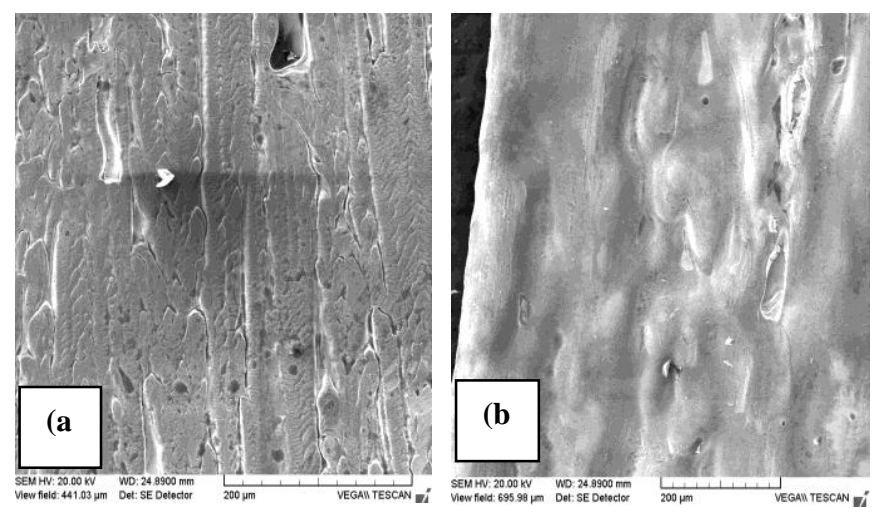

AJSTD Vol.26 Issue 2

Figure 1: Surface morphology cast ribbon (a) quenched side (b) free side

The microstructures of re-melted ingot alloy and rapidly solidified alloy for $\mathrm{Cu} 10 \mathrm{wt} \% \mathrm{Cr}$ alloy and pure $\mathrm{Cu}$ ribbon are shown in Figure 2. The ingot showed the expected two phase structure consisting of $\mathrm{Cu}$ rich matrix and large $\mathrm{Cr}$ precipitates. The ribbons however seem to indicate a single phase with the typical quenching structure consisting of small grains on the quenched side followed by columnar grains towards the free side of the ribbon. EDS and WDS analysis suggest that the ingot matrix is entirely a $\mathrm{Cu}$ phase with a light $\mathrm{Cu}-\mathrm{Cr}$ solution of about $0.8 \mathrm{wt} \% \mathrm{Cr}$ due to the chilling effect, and the precipitate is largely a $\mathrm{Cr}$ phase. The ribbon however did not show resolved phases with EDS and WDS suggesting micro-homogeneous composition close to the nominal composition. The EDS spectral for the microconstituents are shown in Figure 3. The microstructure and the evidence from electron microanalysis seem to suggest complete dissolution and a massive second phase refinement of $\mathrm{Cr}$ at much higher concentration than previously reported for $\mathrm{Cu}-\mathrm{Cr}$ alloys.

In order to determine the extent of solid solution as a result of the rapid solidification, X-ray diffraction was used to identify the phases present in the cast ribbon. Figure 4 shows the XRD spectrum for some as cast ribbon alloys. The fact that the $\mathrm{Cr}$ phase only starts to show at higher concentration of $10 \mathrm{wt}$ percent confirm that a massive solution extension had occurred. Even for the $10 \mathrm{wt} \% \mathrm{Cr}$ alloy, the $\mathrm{Cr}$ lines were weak and broadened which indicates that the $\mathrm{Cr}$ precipitates were refined to extremely small sizes compared to their morphology in the ingot alloys. The extent of solid solution extension could be evaluated from lattice parameter measurements.

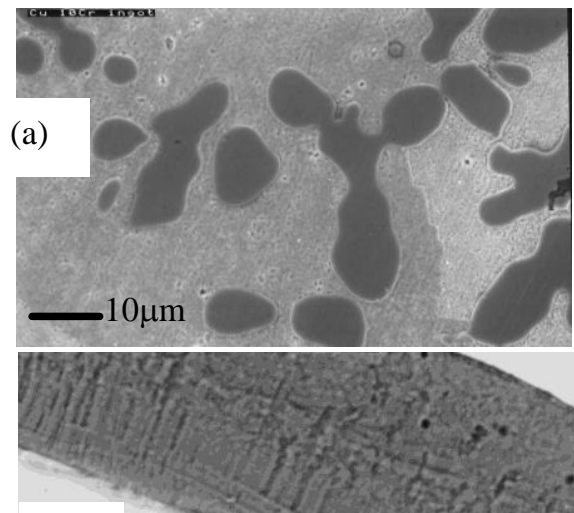

(b)

15

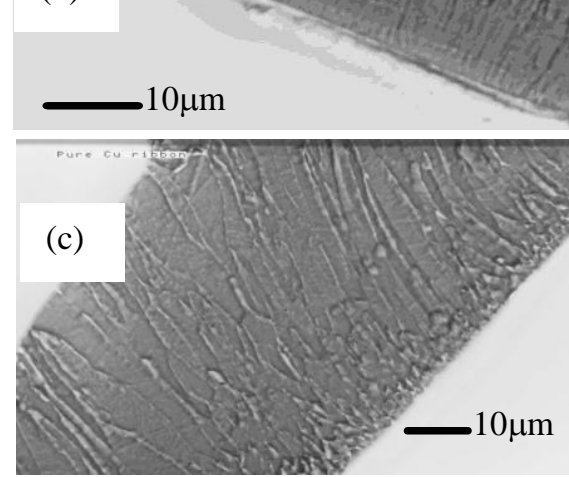

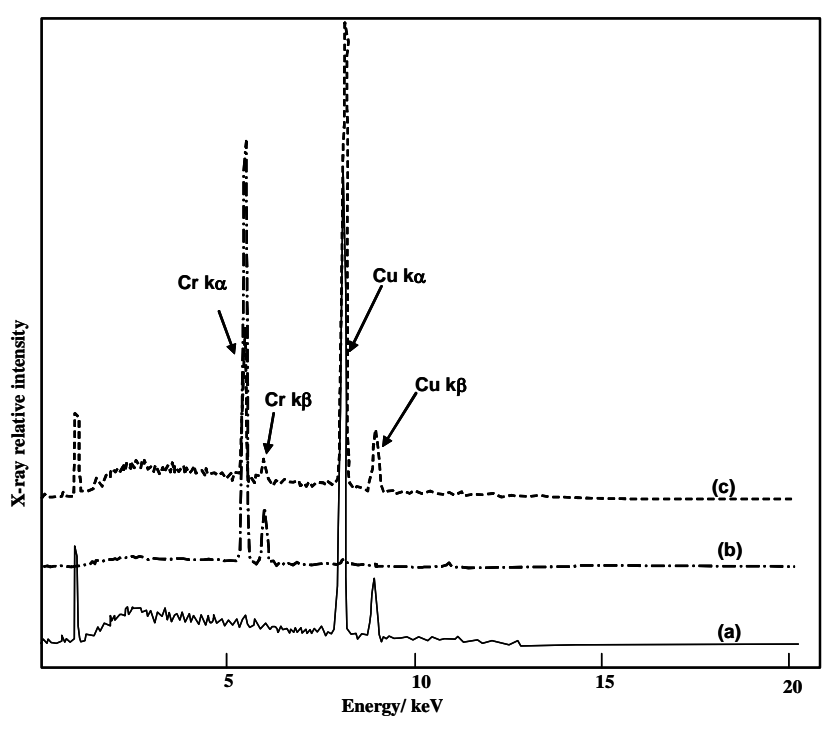

Figure 3: Energy Dispersive X-ray spectrum from samples in Fig.2 (a)matrix from ingot (b) precipitate from ingot (c) section from ribbon alloy 
Processing of the diffraction data, using the five cupper lines and Nelson - Riley parameter [16], indicated a lattice parameter difference of $0.001 \mathrm{~nm}$ for the $10 \mathrm{wt} \% \mathrm{Cr}$ ribbon alloy. Comparing this with published literature data [17] where it was shown that the increase in lattice parameter is linear to 4at\% $\mathrm{Cr}$ at the rate of $2.5 \times 10^{-4}$ per at. $\% \mathrm{Cr}$, seems to suggest that at least 4 at $\% \mathrm{Cr}$ was in solution. However, since the effect is not linear beyond the $4 \mathrm{at} \% \mathrm{Cr}$ in solution, it is well possible that much more was in solution as it seemed from the phase identification. What was apparent however, was that we had a combination of extended solution and extreme second phase refinement.

The effects of $\mathrm{Cr}$ concentration on the hardness and conductivity of as cast ribbon are shown in Figures 5 and 6 . Hardness increases from a value of 70 to a little over $200 \mathrm{Hv}$ for $10 \mathrm{wt} \% \mathrm{Cr}$. Conductivity of asquenched also dropped from $85 \%$ to $10 \%$ IACS as the Cr content increases to $10 \mathrm{wt}$. The change in hardness and conductivity with $\mathrm{Cr}$ content could be fitted to a two linear regime as shown. The first would be consistent with the sole effect of solid solution strengthening while the second regime is where this effect has become less dominant. This observation is consistent with the suggestion from XRD that a solid solution beyond previously published [17] was achieved because we expected that hardness and conductivity in the linear region are entirely due to solid solution. Quite clearly for the 10wt \% alloy, the hardness recorded is a combination of solution and dispersion (precipitate) hardening in conformity with the XRD result shown in Figure 4. The conductivity of 85\%IACS recorded for pure copper ribbon is due to the refined grain structure typical in quenched metals (Figure $2 \mathrm{c}$ ). The hardness and conductivity when annealed reverted to the expected values $50 \mathrm{Hv}$ and $96 \%$ IACS respectively.

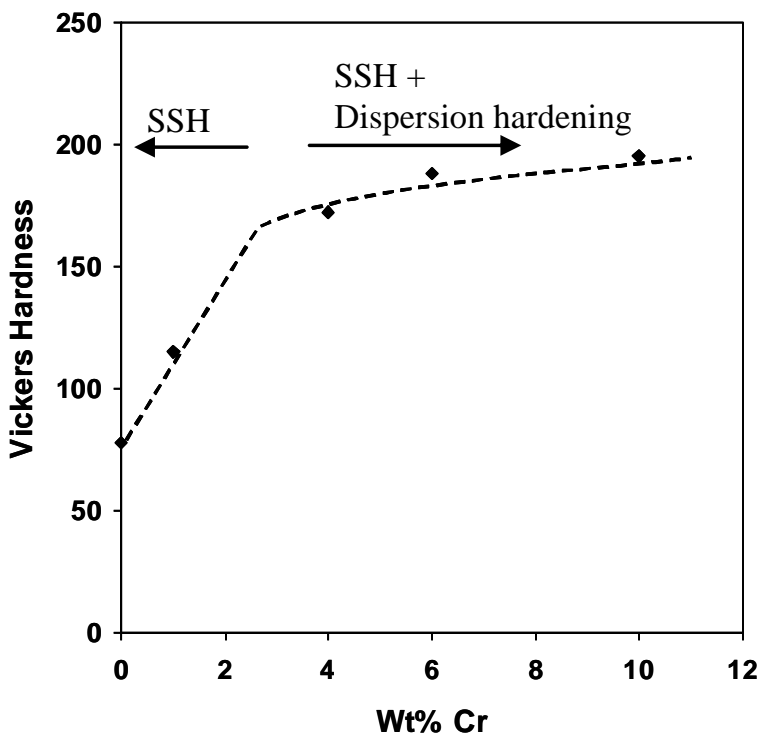

Figure 5: Effect of $\mathrm{Cr}$ concentration on the hardness of cast ribbon

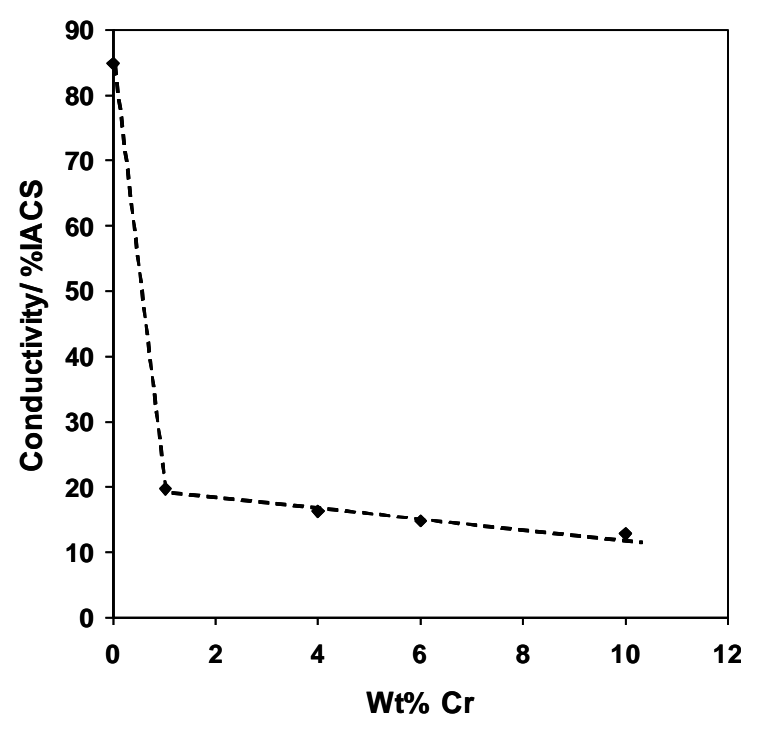

Figure 6: Effect of $\mathrm{Cr}$ concentration on the conductivity of cast ribbon 


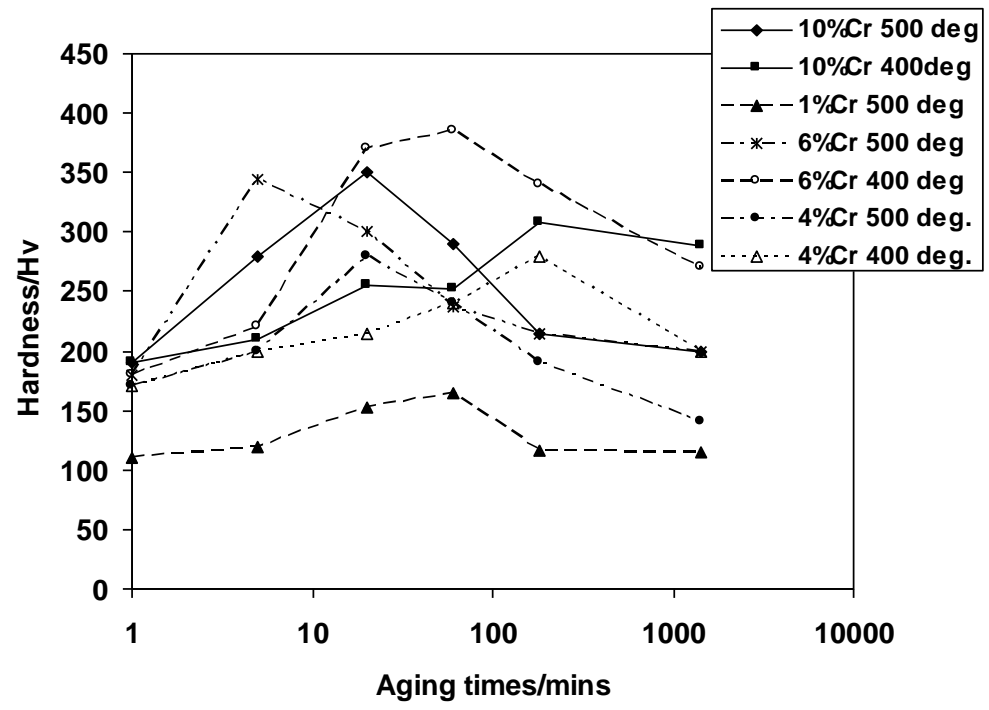

AJSTD Vol.26 Issue 2

Figure 7: Hardness variation with aging time

\subsection{HSHC properties in heat treated alloys}

The confirmation of extended solid solution and the refinement of cast-in precipitates in the cast ribbons are expected to provide the basis for large volume fraction of precipitates on heat treatment. The design strategy is such that the resistivity would drop as the quenched-in solute is forced out as precipitates, and depending on the morphology, mechanical hardness (strength) should also improve. For the alloys studied, the thermal aging was followed by conductivity and hardness measurements at 400 and $500^{\circ} \mathrm{C}$. The trend of hardness and conductivities with aging time are represented in Figures 7 and 8. It is shown that peak hardness was reached in 10 to 20 minutes depending on the $\mathrm{Cr}$ content and the aging temperature. The effects of $\mathrm{Cr}$ on the peak hardness, overage hardness are represented in Figures 8 and 9. The peak hardness increases with $\mathrm{Cr}$ up to $6 \mathrm{wt} \%$. This would be consistent with expected increase in volume fraction of the hardening $\mathrm{Cr}$ precipitates. Beyond the composition $6 \mathrm{wt} \%$, there does not seem to be additional hardness benefit. All the alloys settled to an overage conductivity of about 60\%IACS or higher. Though, the conductivity at peak aged hardness remains slightly lower and depend on $\mathrm{Cr}$ content, the HSHC properties with conductivities ranging 50-60\%IACS and hardness values greater than $200 \mathrm{Hv}$ (yield strength >500MPa), ranks amongst the best HSHC properties ever reported.

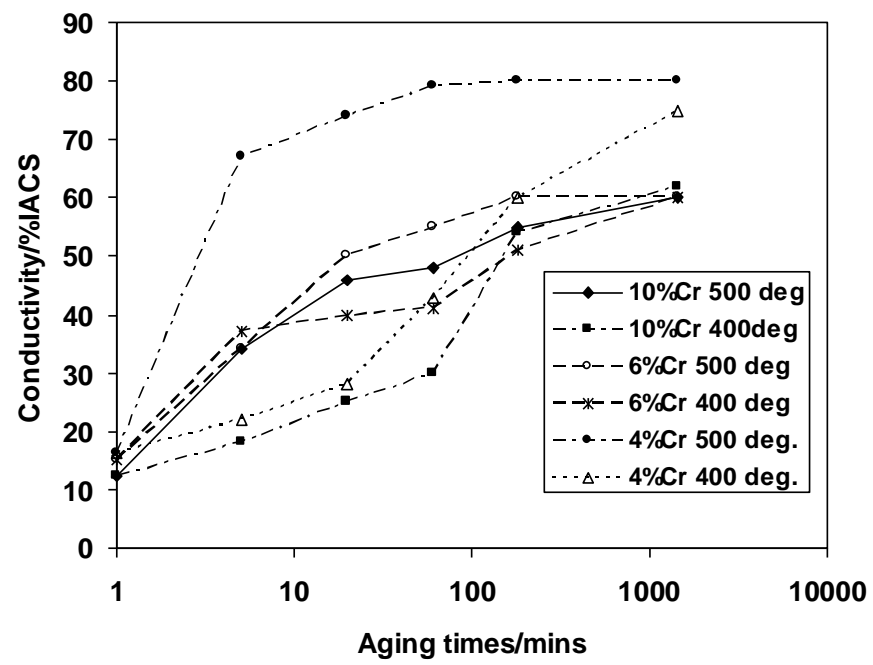

Figure 8: Conductivity variation with aging time

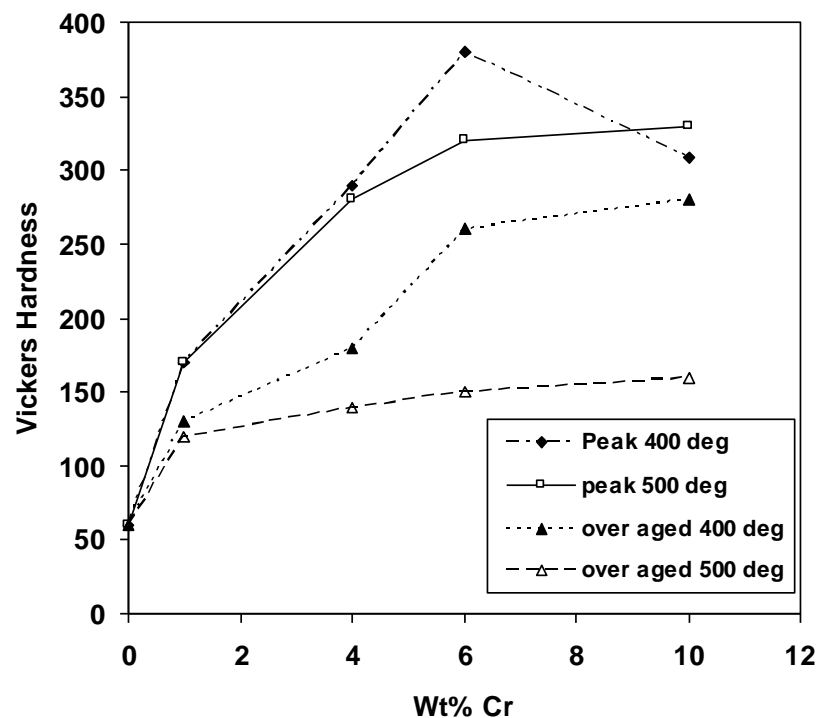

Figure 9: Effect of $\mathrm{Cr}$ content on peak and overaged hardness 


\subsection{Aging and microstructural evolution}

At peak aged condition, the property of $300 \mathrm{Hv}$ and $70 \%$ IACS achieved here ranks amongst the best HSHC properties reported The mechanism of strengthening in these group of alloys has been attributed [18] to coherent finely distributed $\mathrm{Cr}$ particles. The TEM for peak aged alloy and the selected area diffraction pattern from a precipitate are shown in Figure 11. The microstructure shows two groups of precipitates both fine and typically nano-sized. The SADP from the finer group of precipitates shows rings patterns identified to be from bcc nanocrystalline $\mathrm{Cr}$ whereas the background reflection is from ordered reflections corresponding to fcc $\mathrm{Cu}$. The evidence here suggest most of the precipitates are not fully coherent, perhaps because a full crystal structure of bcc $\mathrm{Cr}$ is already established even for the nano sized precipitates. It is possible that earlier clustering of the $\mathrm{Cr}$ atoms might provide the form of coherency proposed in literature [18]. However, the loss of coherency here does not seem to lead to loss of strength. SADP of overaged precipitate gives reflections consistent with bcc crystalline $\mathrm{Cr}$ thus signifying that precipitates growth rather than loss of coherency is responsible for reduced strength in the overaged condition.

The rapidity of overaging in this alloy group is still a cause for concern. We would expect that a rapidly solidified metallic alloy would exist in a high state of metastability and as a result would contain a very high concentration of quenched-in vacancies; much more than would be found in conventionally cast alloy at room temperature. At the ageing temperatures, there would be a tendency for vacancies to form vacancy clusters which probably would collapse into dislocation loops that can grow more by absorbing more vacancies. It is quite reasonable to imagine in many ways how the excess vacancies are able to provide heterogeneous nucleation sites for the trapped solute $\mathrm{Cr}$ atoms. The excess vacancies also would provide a diffusion path by decreasing the diffusion coefficient of $\mathrm{Cr}$ by several orders of magnitude. The TEM microstructure showing cohorts of precipitate sizes provide the evidence for the existence of quenched in Cr particles. It would seem plausible to associate the larger size with those that originates from quenched in clusters or nuclei. Both the presence of excess vacancies and the quenched in $\mathrm{Cr}$ atom clusters combined to provide a lower energy path and a kinetically favored nucleation and growth of $\mathrm{Cr}$ bcc phase, thus the rapidity of overaging encountered. The HSHC properties in the overaged condition are still more than modest. The hardness was still well over $200 \mathrm{Hv}(\sim 500 \mathrm{MPa})$ and conductivity above $60 \%$ IACS. It would still be beneficial if the peak aged condition can be stabilized to reduce the risk of overaging. The reasonable approach would be to apply alloying strategy that would stabilize the $\mathrm{Cr}$ precipitates against growth. $\mathrm{Zr}$ and $\mathrm{Ti}$ have been found to provide high temperature stabilities to $\mathrm{HSHC} \mathrm{Cu}$ alloys and it remain to be seen whether similar addition in this group of alloys could provide similar benefits. 


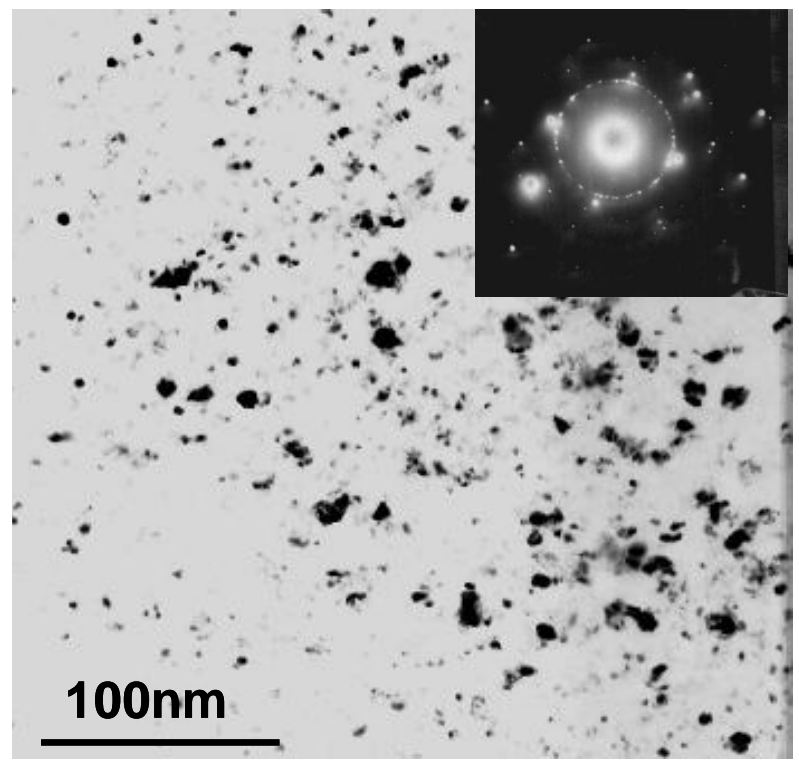

Figure 10: (a) TEM Bright field image from a peak aged $10 \%$ Cr ribbon, inset shows SADP from a precipitate

\section{Conclusions}

High strength high conductivity properties were achieved in high $\mathrm{Cr} \mathrm{Cu}-\mathrm{Cr}$ rapidly solidified alloys. The semi chilling of the ingot making process provided a means of preparing a homogenized ingot for the meltspining process. The rapid solidification indicated extension of solid solubility and extreme refinement of the second phase $\mathrm{Cr}$. The quenched ribbon was peak aged to give a combination of hardness higher than $300 \mathrm{Hv}$ which would correspond to yield strength of 900 to $1000 \mathrm{MPa}$ and a conductivity of 70\%IACS. These alloys however are susceptible to quick overaging. The overaging is believed to arise because of the high state of the physical and chemical meta-stability imposed by the rapid quenching. The combination of the chemical potential drive and the quenched in vacancies allowed a thriving atmosphere for nucleating and growth of second phase precipitates. It is thought that the precipitates can be stabilized against growth by alloying further with transition elements that are known to stabilized precipitate coalesce.

\section{Acknowledgements}

AO express gratitude to Unuiversiti Brunei Darussalam for funds provided through grant No $\mathrm{UBD} / \mathrm{PNC} 2 / \mathrm{RG} / 1(24)$. The rapidly solidified ribbon used in this work was produced in the laboratory of the Department of Engineering Materials, University of Queensland under the supervision of Prof. A Atrens.

\section{References}

[1] K. Han, R. P. Walsh, A. Ishmaku, V. Toplosky, L. Brando and J.D. Embury, High Strength and high electrical conductivity of bulk Cu, Phil. Mag. Vol. 84, No.34 (2004), 3705 - 3716.

[2] P. Liu, J. Su, Q. Dong, and H. Li, Optimization of aging treatment in lead frame copper alloy by intelligent technique, Mater. Lett. Vol 59 (2005) 3337 - 3342.

[3] Zhenyu Li, Jun Shen, Fuyang Cao, Qingchun Li, A high strength and high conductivity copper alloy prepared by spray forming, J. Mater. Proc Tech. 137 (2003) $60-64$. 
[4] R. Markandeya, S. Nagarjuna and D.S. Sarma, Precipitation hardening of $\mathrm{Cu}-\mathrm{Ti}-\mathrm{Cr}$ alloys Mater Sci \& Engr A,371 (2004) $291-305$.

[5] M. M. Dadras and D. G. Morris, Examination of some high strength high conductivity copper alloys for high temperature applications, Script Met. Vol 38 (1998) 199 - 205.

[6] N. Gao, E. Huttunen-Saarivirta, T. Tianen, and M. Hemmila, Influence of prior deformation on the age hardening of a phosphorus-containing $\mathrm{Cu}-0.61 \mathrm{wt} . \% \mathrm{Cr}$ alloy Mater Sci \& Engr A,342 (2003) $270-278$.

[7] J. Su, Q. Dong, P. Liu, H. Li, B. Kang, Research on aging precipitation in a $\mathrm{Cu}-\mathrm{Cr}-\mathrm{Zr}-\mathrm{Mg}$ alloy Mater Sci \& Engingr A,392 (2005) 422-426.

[8] J. B. Correia, H. A. Davies, C. M. Cellars, Strengthening in rapidly solidified age hardened $\mathrm{Cu}-\mathrm{Cr}$ and Cu-Cr-Zr alloys Act. Mater. Vol 45 (1997) 177-190.

[9] J. B. Correia and H. A. Davies, Magnetic and structural monitoring of nanophase precipitation during ageing of water-atomised $\mathrm{Cu}-5 \%$ Co alloy powders, Act Mater. Vol 48, (2000) 4115-4123.

[10] M. A. Morris and D. G. Morris, Microstructures and mechanical properties of rapidly solidified CuCr alloys, Act. Met. Vol 35, (1987) 2511-2522

[11] P Liu, BX Kang, XG Cao, JL Huang, HC Gu, Strengthening mechanisms in a rapidly solidified and aged $\mathrm{Cu}-\mathrm{Cr}$ alloy Journal of materials science, 35, (2000) $1691-1694$.

[12] F. Lopez, J. Reyes, B. Campillo, G. Aguilar and J.A. Juarez-lslas, Rapid solidification of copper alloys with high strength and high conductivity, JMEPENG vol 6 (1997) 611-614

[13] J. Strobrawa, Z. Rdzawski, Dispersion strengthened nanocrystalline copper, Journal of Achievements in Materials and Manufacturing Engineering, Vol. 24 (2007) 35-41.

[14]E. Botcharova, M. heilmaier, J. freudenberger, G. Drew, D. kudashow, U. Martin, L. Schultz, Supersaturated solid solution of niobium in copper by mechanical alloying J. Alloys \& Compds, vol. 351 (2003) $119-125$.

[15] A. O. Olofinjana, and H. A. Davies, Mater. Sci. Engr. Vol A186, (1994) 143-149

[16] J. Dutta Majumdar, I. Manna, Laser surface alloying of copper with chromium Mater. Sci. Engr. Vol A268, (1999) 215-226

[17] A. Bell and H. A. Davies, Solid solubility extension in $\mathrm{Cu}-\mathrm{V}$ and $\mathrm{Cu}-\mathrm{Cr}$ alloys produced by chill block melt-spinning Mater. Sci. Engr. Vol A226 - 228 , (1997) 1039-1041

[18] H. Fernee, J. Nairn, A. Atrens, Precipitation hardening of Cu-Fe-Cr alloys part I J. Mater. Sci, vol. 36 (2001) $2711-2719$. 